\title{
Хромато-масс-спектрометрический анализ маршрута реакции между 1,2-диаминоимидазолом и 1-арил-3-(диметиламино)проп-2-ен-1-оном
}

\author{
Вандышев Д.Ю., Шихалиев Х.С., Потапов А.Ю., \\ Крысин М.Ю., Коконова А.В. \\ ФГБОУ ВО «Воронежсский государственный университет», Воронеж
}

Поступила в редакцию 7.03.2017 г.

\begin{abstract}
Методом ВЭЖХ совмещенной с масс-спектрометрией изучен маршрут реакции гетероциклизации между 1,2-диамино-4-фенилимидазолом и 1-фенил-3-(диметиламино)проп-2-ен-1-оном.

Ключевые слова. Высокоэффективная жидкостная хроматография, масс-спектрометрия, диаминоимидазол, енаминоны, реакционная масса, имидазопиридазины.
\end{abstract}

\section{Chromato-mass-spectrometric analysis of the reaction between 1,2-diaminoimidazole and 1-aryl-3-(dimethylamino)prop-2-en-1-one}

\author{
Vandyshev D. Yu., Shikhaliev Kh. S., Potapov A. Yu., \\ Krysin M. Yu., Kokonova A.V. \\ VoronezhStateUniversity, Voronezh
}

\begin{abstract}
Diaminoimidazoles are actively used in the creation of various substances with a given physiological activity. However, the main problem in the chemistry of this polynucleophilic substrate is: the determination of the sequence of transformations leading to final products during various cascade processes, as well as the time that is necessary to form the maximum number of desired substances. By the method of highperformance liquid chromatography in combination with mass spectrometry, we studied the interaction of 1,2-diaminoimidazole with 1-phenyl-3-(dimethylamino)prop-2-en-1-one. In the course of the analysis, it was found that the reaction takes place over two hours of boiling and leads to a single product - 4-phenyl-5phenylimidazo[1,5-b]pyridazine-7-amine.
\end{abstract}

Keywords. High performance liquid chromatography, mass spectrometry, diaminoimidazole, enaminone, the reaction mass, imidazopyridine.

\section{Введение}

Фрагмент аминоимидазолов привлекает особое внимание исследователей уже более ста лет благодаря своей практической и теоретической значимости. В первую очередь это объясняется тем, что имидазол и его конденсированные системы содержатся в продуктах природного происхождения и выполняют важную роль в биохимических процессах. Среди всех возможных производных этой гетероциклической матрицы особое внимание сосредоточено на имидазопиридазинах, которые нашли широкое применение в различных сферах жизни. Наиболее значимым является использование их в медицине. В частности, для производных имидазопиридазинов вы- 
явлена активность в отношении онкологических [1], эпилептических [2] и малярийных заболеваний [3].

\section{Теоретическая часть}

Среди вариантов сочленения имидазольного и пиридазинового колец наиболее актуальны имидазо[1,2-b]пиридазины и имидазо[1,5-b]пиридазины, причем последние исследованы в меньшей степени. Подходы к построению этих систем весьма различны, однако большинство из них являются длительными и требуют использование труднодоступных реагентов $[4,5]$. В связи с этим наиболее оптимальным при построении имидазопиридазинов является использование 1,2-диамино-4фенилимидазолов.

Образование имидазо[1,5-b]пиридазинов с использованием диаминоимидазолов отмечено в реакциях с ацетиларенами и кетоэфирами [6], дикетонами [7], ароилакриловыми кислотами [8] и в различных многокомпонентных процессах $[9,10]$. Однако, основной проблемой при исследовании каскадных реакций с использованием этой полинуклеофильной матрицы является определение последовательности процессов, приводящих к целевым продуктам. Для реализации этой задачи необходимы сведения о строении промежуточных соединений, возможность индивидуализации которых весьма затруднительна. Поэтому для решения подобных проблем все чаще стали использовать масс-спектрометрию в сочетании с жидкостной хроматографией, позволяющей анализировать составы интермедиатов и конечных продуктов реакций, проходящих в жидкой фазе, без выделения их из реакционной массы [1115]. В связи с этим, целью данного исследования является изучение взаимодействия 1,2-диаминоимидазола с 1-фенил-3-(диметиламино)проп-2-ен-1-оном с использованием хромато-масс-спектрометрического метода анализа.

\section{Эксперимент}

Контроль за механизмом реакции осуществлялся методом ВЭЖХ/МС на установке, включающей жидкостный хроматограф Agilent 1269 Infinity и времяпролетный детектор масс высокого разрешения Agilent 6230 TOF LC/MS. Метод ионизации - двойное электрораспыление, регистрация в положительной полярности, диапозон регистрируемых масс 50-2000 Да, напряжение на капилляре 4.0 кВ, фрагменторе 191 В, скиммере 66 B, OctRF 750 В. Колонка Poroshell 120 EC-C18 (4.6 x 50 мм, 2.7 мкм). Градиентное элюирование: ацетонитрил-вода (0.1 \% муравьиной кислоты), скорость потока 0.4 мл/мин. Програмное обеспечение для сбора и обработки результатов исследования - MassHenter Workstation/Data Acquisition V.06.00.

\section{Обсуждение результатов}

Реакцию диаминоимидазола 1 с енаминоном 2 проводили в при кипячении в диметилформамиде в присутствии каталитического количества уксусной кислоты в течение нескольких часов. ВЭЖХ/МС анализ в сочетании с УФ детектированием проводился путем фиксирования масс полупродуктов и продуктов реакции. Пробы отбирались из реакционной массы через определенные промежутки времени: 10, 30, 60 и 120 минут. 


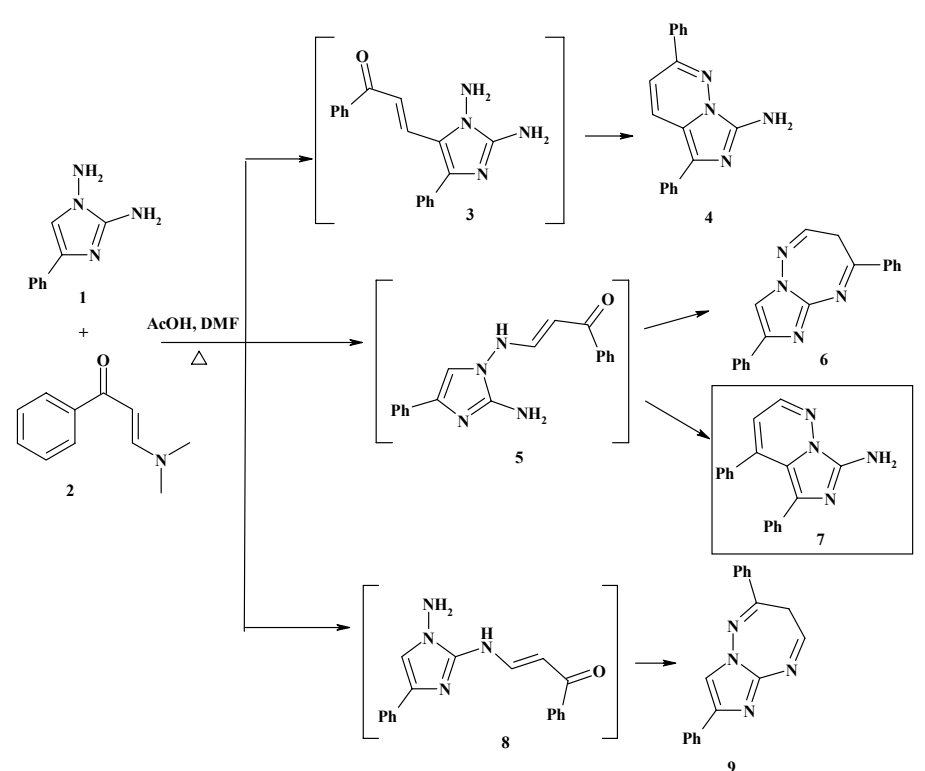

На приведенных ниже хроматограммах (рис. 1-4) можно увидеть, что в ходе процесса помимо исходных реагентов, фиксируются пики возможных интермедиатов и продуктов реакции, имеющих массу протонированного иона 305 и 287 соответственно. На основании данных о реакционной способности 1,2-диамино-4фенилимидазола 1 , а так же на основании спектра ЯМР ${ }^{1} \mathrm{H}$ и РСА полученного соединения 7, нами были сделаны следующие выводы при интерпретации результатов хроматографического анализа.

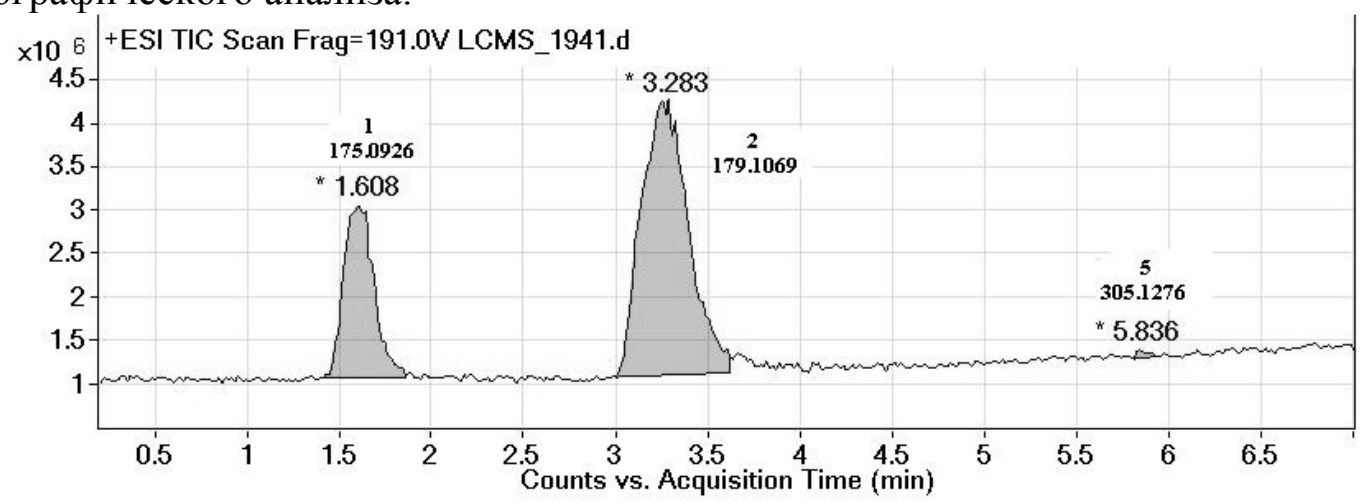

Рис. 1. Интегрированная сканированная хроматограмма полного ионного тока реакционной смеси. Время реакции 10 минут.

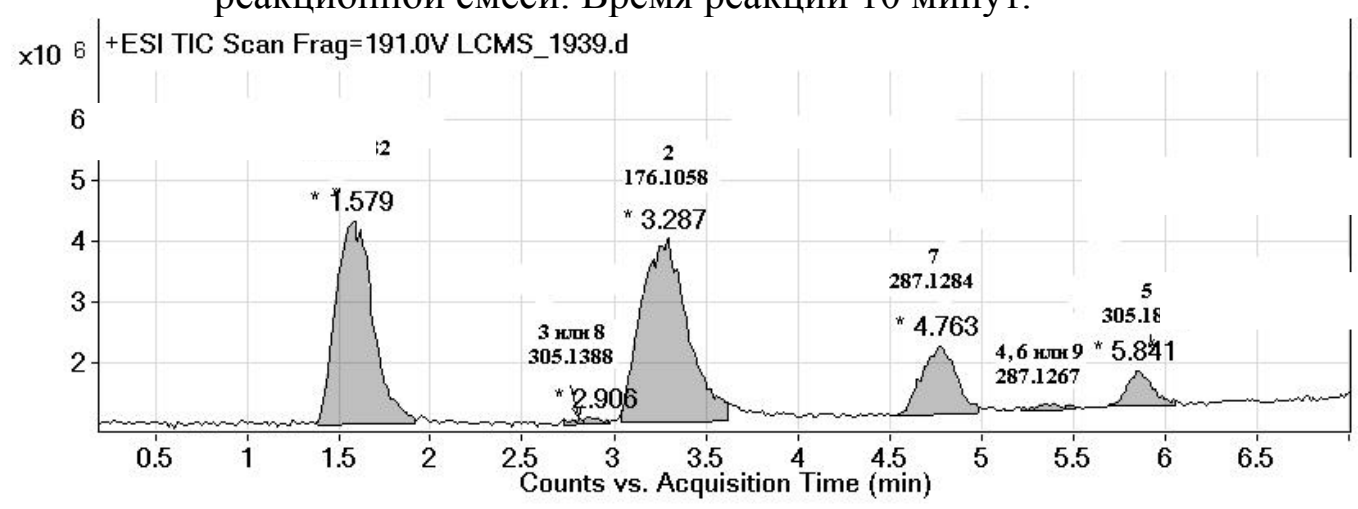

Рис. 2. Интегрированная сканированная хроматограмма полного ионного тока реакционной смеси. Время реакции 30 минут.

При смешивании реагентов и кипячении в течение 10 минут в реакционной массе сразу начинает образовываться интермедиат 5 (сигнал при 5.836 мин.). С тече- 
нием времени (30 и 60 минут), концентрация исходных реагентов начинает уменьшаться, появляются сигналы соответствующие возможным интермедиатам - аминоимидазолилпропенонам $3,5,8$ и конечным продуктам - имидазопиридазинам 4,7 и имидазотриазипинам 6,9 . После двух часов кипячения в реакционной массе фиксируются пики конечного продукта 7 (4.749 мин), альтернативных продуктов 4, 6 или 9 (5.312 мин.) и интермедиата 5 (5.876 мин.). Необходимо отметить, что после двухчасового кипячения имидазопиридазин 7 начинал выпадать в осадок, что сильно влияло на результаты дальнейшего анализа.

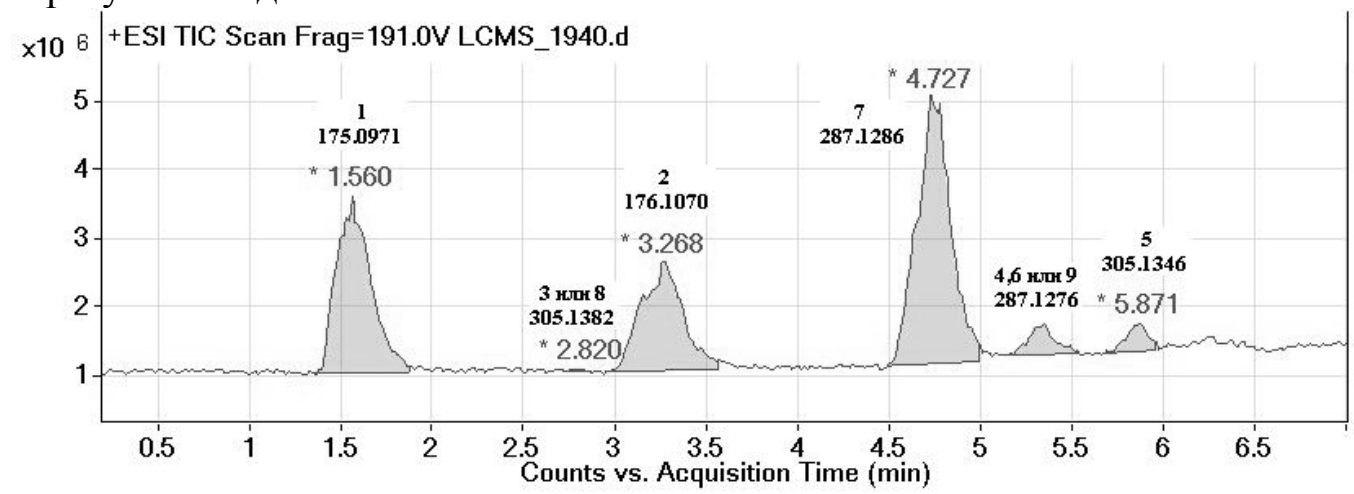

Рис. 3. Интегрированная сканированная хроматограмма полного ионного тока реакционной смеси. Время реакции 60 минут.

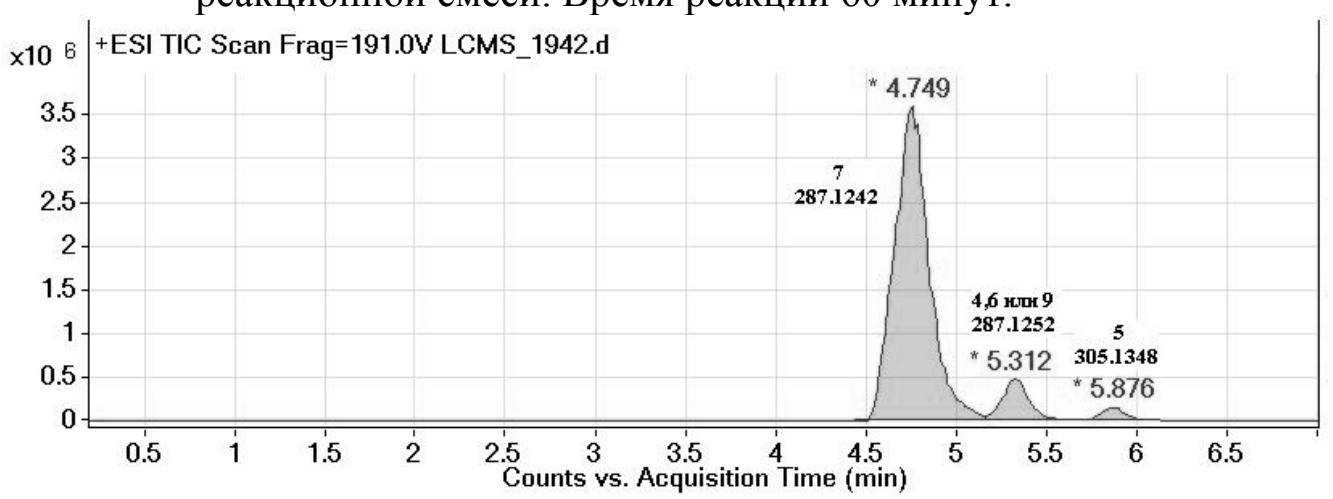

Рис. 4. Интегрированная сканированная хроматограмма полного ионного тока реакционной смеси. Время реакции 120 минут.

После охлаждения реакционной массы, осадок был отфильтрован и проанализирован. Хроматограмма содержит сигнал конечного продукта реакции - 4-фенил-5фенилимидазо[1,5-b]пиридазин-7-амина 7 - при 4.717 мин $\left(m / z 287.1297[\mathrm{M}+\mathrm{H}]^{+}\right)$. Выход составляет $92 \%$ от теоретически возможного

\section{Заключение}

Таким образом, реакция между 1,2-диамино-4-фенилимидазолом и 1-фенил-3(диметиламино)проп-2-ен-1оном протекает в течение двух часов и приводит, через стадии образования интермедиатов - аминоимидазолилпропенонов, к образованию 4-фенил-5-фенилимидазо[1,5-b]пиридазин-7-амина.

\section{Список литературы}

1. Huang W. S., Metcalf C. A., Sundaramorthi Chemistry. 2010. Vol. 53. No 12. pp. 4701R., Wang Y. et al.. // Journal of Medicinal 4719. 
2. Miller G.D., Woessner D.W., Sirch M.J., Lim C.S. // Molecular Pharmaceutics. 2013. Vol. 10. No 9. pp. 3475-3483.

3. Foulks J.M., Carpenter K.J., Luo B., XuY. et al. // Neoplasia. 2014. Vol. 16. No 5. pp. 403412.

4. Roberts L.R., Bradley P.A., Bunnage M.E., England K.S. et al // Bioorganic and Medicinal Chemistry Letters. 2011. Vol. 21. No 21. pp. 6515-6518.

5. Livermore D.G.H., Bethell R.C., Cammack N., Hancock A.P. et al. // Journal of Medicinal Chemistry. 1993. Vol. 36. No 24. pp. 37843794.

6. Kolos N.N., Orlov V.D., Paponov B.V., Baumer V.N. // Chemistry of Heterocyclic Compounds. 1998. Vol. 34. No 10. pp. 11891194.

7. Kolos N.N., Kovalenko L.Yu., Shishkina S.V., Shishkin O.V. et al. // Chemistry of Heterocyclic Compounds. 2007. Vol. 43. No 3. pp. 1397-1405.

8. Kutlescha K., Irragang T., Kempe R. // Advanced Synthesis and Catalysis. 2010. Vol. 352. No 18. pp. 3126-3130.

\section{References}

1. Huang W.S., Metcalf C.A., Sundaramorthi R., Wang Y. et al., Journal of Medicinal Chemistry, 2010, Vol. 53, No 12, pp. 4701-4719.

2. Miller G.D., Woessner D.W., Sirch M.J., Lim C.S., Molecular Pharmaceutics, 2013, Vol. 10, No 9, pp. 3475-3483.

3. Foulks J.M., Carpenter K.J., Luo B., Xu Y. et al., Neoplasia, 2014, Vol. 16, No 5, pp. 403412.

4. Roberts L.R., Bradley P.A., Bunnage M.E., England K.S. et al., Bioorganic and Medicinal Chemistry Letters, 2011, Vol. 21, No 21, pp. 6515-6518.

5. Livermore D.G.H., Bethell R.C., Cammack N., Hancock A.P. et al., Journal of Medicinal Chemistry, 1993, Vol. 36, No 24, pp. 37843794.

6. Kolos N.N., Orlov V.D., Paponov B.V., Baumer V.N., Chemistry of Heterocyclic Compounds, 1998, Vol. 34, No 10, pp. 1189-1194.

7. Kolos N.N., Kovalenko L.Yu., Shishkina S.V., Shishkin O.V. et al., Chemistry of Heterocyclic Compounds, 2007, Vol. 43, No 3, pp. 1397-1405.
9. Lipson V.V., Svetlichnaya N.V., Shirobokov M.G., Musatov V.I. et al. // Russian Journal of Organic Chemistry. 2012. Vol. 48. No 2. pp. 273-277.

10. Lipson V.V., Svetlichnaya N.V., Shishkina S.V., Shishkin O.V. // Mendeleev Communication. 2008. Vol. 18. No 4. pp. 141 -143.

11. Medvedeva S.M., Shikhlaliev K.S., Krysin M.Y., Gotsak I.V. // Chemistry of Heterocyclic Compounds. 2016. Vol. 52. No 5. pp. 309-315.

12. Шихалиев Х.С., Селеменев В.Ф., Медведева С.М., Пономарева Л.Ф. и др. // Сорбиионные и хроматографические прочессы. 2014. T. 14. № 2. C. 332-337.

13. Медведева С.М., Шихалиев Х.С. // Сорбиионные и хроматографические проиессы. 2014. Т. 14. № 4. С. 696-702.

14. Медведева С.М., Шихалиев Х.С., Крыльский Д.В., Синяева Л.А. // Сорбиионные и хроматографические проиессы. 2014. T. 14. № 6. C. 970-976.

15. Vandyshev D.Yu., Shikhaliev, Kh.S., Kokonova, A.V. et al. // Chemistry of Heterocyclic Compounds. 2016. Vol. 52. No 7. pp. 493-497.

8. Kutlescha K., Irragang T., Kempe R., $A d$ vanced Synthesis and Catalysis, 2010, Vol. 352, No 18, pp. 3126-3130.

9. Lipson V.V., Svetlichnaya N.V., Shirobokov M.G., Musatov V.I.,et al., Russian Journal of Organic Chemistry, 2012, Vol. 48, No 2, pp. 273-277.

10. Lipson V.V., Svetlichnaya N.V., Shishkina S.V., Shishkin O.V., Mendeleev Communication, 2008, Vol. 18, No 4, pp. 141 -143.

11. Medvedeva S.M., Shikhlaliev Kh.S., Krysin M.Yu., Gotsak I.V., Chemistry of Heterocyclic Compounds, 2016, Vol. 52, No 5, pp. 309-315.

12. Shihaliev Kh.S., Selemenev V.F., Medvedeva S.M., Ponomareva L.F. et al., Sorbtsionnye $i$ khromatograficheskie protsessy,2014, Vol. 14, No 2, pp. 332-337.

13. Medvedeva S.M., Shihaliev Kh.S., Sorbtsionnye i khromatograficheskie protsessy, 2014, Vol. 14, No 4, pp. 696-702.

14. Medvedeva S.M., Shihaliev Kh.S., Kryl'skij D.V., Sinjaeva L.A., Sorbtsionnye $i$ khromatograficheskie protsessy, 2014, Vol. 14, No 6, pp. 970-976. 
15. Vandyshev D.Yu., Shikhaliev Kh.S., lic Compounds, 2016, Vol. 52, No 7, pp. 493Kokonova A.V. et al., Chemistry of Heterocyc- 497.

Вандышев Дмитрий Юрьевич - аспирант кафедры органической химии химического факультета ВГУ, Воронеж

Шихалиев Хидмет Сафарович - д.Х.н., проф., заведующий кафедрой органической химии ВГУ, Воронеж

Потапов Андрей Юрьевич - д.х.н, доцент кафедры органической химии ВГУ, Воронеж

Крысин Михаил Юрьевич - д.х.н., профессор кафедры органической химии ВГУ, Воронеж

Коконова Анна Владимировна - магистр 2 года обучения химического факультета ВГУ, Воронеж.
Vandyshev Dmitriy Yu. - the postgraduate student of organic chemistry department, Voronezh State University, Voronezh. e-mail: cy2007@mail.ru

Shikhaliev Khidmet S. - professor, head of Department of Organic Chemistry, Voronezh State University, Voronezh

Potapov Andrey Yu. - dr. sci., associate professor of organic chemistry department, Voronezh State University, Voronezh.

Krysin Michael Yu. - professor of organic chemistry department

Kononova Anna V. - student, Voronezh State University, Voronezh 